|| ISSN(online): 2589-8698 || ISSN(print): 2589-868X || International Journal of Medical and Biomedical Studies

Available Online at www.ijmbs.info

PubMed (National Library of Medicine ID: 101738825)

Index Copernicus Value 2018: 75.71

Original Research Article

Volume 3, Issue 5; May: 2019; Page No. 151-155

\title{
SERUM MAGNESIUM LEVEL IN DIABETIC RETINOPATHY - A CROSS SECTIONAL STUDY
}

\section{Dr. I. Vijayapriya ${ }^{1}$, Dr. Prakash. ${ }^{2}$, Dr. S. Hemadharshini ${ }^{3}$}

${ }^{1} \mathrm{MD}$ (Biochemistry), Assistant Professor, Department of Biochemistry, Dhanalakshmi Srinivasan Medical College \& Hospital, Perambalur

${ }^{2} \mathrm{MD}$ (Ophthalmology), Assistant Professor, Department of Ophthalmology, Dhanalakshmi Srinivasan Medical College \& Hospital, Perambalur

${ }^{3} \mathrm{CRRI}$, Department of Internal Medicine, Dhanalakshmi Srinivasan Medical College \& Hospital, Perambalur

Article Info: Received 26 April 2019; Accepted 25 May. 2019

DOI: https://doi.org/10.32553/ijmbs.v3i5.257

Corresponding Author: Dr. I. Vijayapriya, MD (Biochemistry), Assistant Professor, Department of Biochemistry, Dhanalakshmi Srinivasan Medical College \& Hospital, Perambalur

Conflict of interest: No conflict of interest.

\section{Abstract:}

Background: Among different complications of diabetes, ddiabetic retinopathy is one of the leading causes of blindness in the world. Increase in the frequency of lower serum magnesium levels have been reported among patients with diabetes.

Materials and methods: A total of 120 subjects were included in this study and divided into 3 groups. The study groups consisted of 40 patients that are type 2 diabetes with retinopathy and 40 patients with type 2 diabetes without retinopathy and control group consisted of 40 healthy subjects respectively. Both cases and controls were subjected to estimation of biochemical parameters.

Results: Among the study population, (80) 66.67\% participants were cases and another (40) 33.33\% participants were controls. Among the people who had mild NPDR, the median Mg was 1.90 (IQR 1.80, 2.00). It was 1.90 $(1.70,2.00), 1.75(1.67,1.92), 1.8(1.69,2.0)$ and $2.10(1.90,2.20)$ among people with DM retinopathy moderate NPDR, severe NPDR, Proliferative retinopathy and no retinopathy respectively. The difference in the Mg across $D M$ retinopathy was statistically significant ( $P$ Value 0.008 ). The difference between the values among both the case and control groups for certain parameters such as SBP, FBG, PPBG, HbA1c, Magnesium, Urea, and Creatinine were found to be statistically significant.

Conclusion: Serum magnesium levels were significantly lower in patients with diabetic retinopathy compared to diabetics without complications and control group.

Keywords: Diabetes mellitus, Diabetic retinopathy, Magnesium

\section{Introduction}

Complications of diabetes are mainly due to metabolic alterations. Retinopathy, neuropathy and nephropathy are among the chronic complications of diabetes. Diabetes and related complications are linked with long-term damage and failure of various organ systems. ${ }^{1}$

Retinopathy, a complication of diabetes, is one of the leading causes of blindness in the world. With different treatment modalities, its incidence can be decreased up to $90 \% .{ }^{2}$ International Clinical Diabetic Retinopathy Scale, categorizes diabetes retinopathy into Non Proliferative (NPDR) and Proliferative Diabetic Retinopathy (PDR). ${ }^{3}$ Non proliferative retinopathy categorised into mild, moderate and severe. Mild NPDR characterised by microaneurysms. Severe NPDR characterised by intra retinal haemorrhages in each of four quadrants, venous beading in two or more quadrants, prominent intra retinal microvascular anomalies in one or more 
quadrants. Findings between mild and severe comprises moderate NPDR. Proliferative Diabetic Retinopathy characterised by neovascularisation and or vitreous or preretinal haemorrhage.

A study by Kundu et $\mathrm{al}^{2}$ labels hypomagnesemia as a marker for risk of development of retinopathy in diabetic patients with mean magnesium levels of $1.30 \pm 0.39$ in patients with diabetic retinopathy. Magnesium, fourth most abundant cation in the body, distributed in bones, intra cellular fluid and extra cellular fluid. It acts as cofactor for kinases and various other enzymes in cells and essential for mediating insulin's mechanism of action. Clinically, hypomagnesemia may be defined as a serum $\mathrm{Mg}$ concentration $\leq 1.6 \mathrm{mg} / \mathrm{dl}$ or $>2 \mathrm{SD}$ below the mean of the general population. ${ }^{4}$ Magnesium (Mg) has a critical role in the actions of important enzymes and it is claimed that there is an converse relationship between $\mathrm{Mg}$ intake and incidence of diabetes mellitus (DM) $)^{5}$. Magnesium levels are reported to be low at an increased frequency among patients with type- 2 Diabetes and the cause is osmotic diuresis.

Hypomagnesemia is a common observation among patients with type 2 diabetes. Even though diabetes can initiate hypomagnesaemia, magnesium deficiency has also been proposed as a risk factor for type 2 diabetes mellitus. Magnesium is a essential cofactor for several enzymes that play an important role in the metabolism of glucose. An estimated 25 to $39 \%$ people with diabetes have low concentrations of serum magnesium ${ }^{6}$. In terms of gender difference, independent studies have reported a higher incidence of hypomagnesaemia in women compared with men, at a 2:1 ratio. 17 In addition, men with diabetes may have higher ionized levels of $\mathrm{Mg}{ }^{7}$ Out of all the micronutrients identified as potential therapeutic agents, magnesium has been investigated as a clinically significant electrolyte for type 2 diabetes mellitus and their complications. ${ }^{8}$ This study was conducted to evaluate the association of serum magnesium levels with diabetic retinopathy among diabetic patients.

\section{OBJECTIVES}

1. To estimate serum magnesium level among diabetic patients with and without retinopathy and compared with healthy age and sex matched control groups
2. To determine the association between serum magnesium level and Diabetic Retinopathy

\section{MATERIAL AND METHODS}

This current cross-sectional study was carried out in the Department of Internal Medicine, Department of Ophthalmology and Department of Biochemistry in DSMCH. This study was carried out on 120 subjects, who were further divided into 3 groups. The study groups involved 40 patients, who were diagnosed with Type 2 Diabetes mellitus with retinopathy, 40 patients with Type 2 Diabetes mellitus and were without retinopathy. The control group comprised of the 40 healthy subjects. Matching was done according to age and sex among the three groups. Informed consent was obtained from all the participants after explaining about the purpose of the study. A pre structured proforma was used to collect the data. Fasting and post prandial venous blood were collected from both study as well as control groups. Serum obtained was utilized for the estimation of fasting blood glucose and magnesium by using commercially available kit in fully automated analyser. Diabetic retinopathy was diagnosed by FUNDUS examination.

Statistical Analysis: The data was analyzed using IBM SPSS statistical software version 21. SBP, DBP, PR, FBG, PPBG, HbA1c, Mg, Urea, and Creatinine were considered as primary outcome variable. Study group (Cases Vs control) was considered as primary explanatory variable. For non-normally distributed Quantitative parameters, Medians and Interquartile range (IQR) were compared between study groups using Kruskal Wallis test. $\mathrm{P}$ value $<0.05$ was considered statistically significant

\section{RESULTS}

This cross-sectional study was conducted among a total study population of 120 who were divided into cases $(n=80)$ and controls $(n=40)$, based on the diagnosis of diabetic retinopathy. Cases were divided into Group 1and Group 2 who were diabetic patients with retinopathy and without retinopathy respectively. The mean age of subjects in cases was $56.51 \pm 9.59$ years and it was $44.4 \pm 10.72$ years in controls. The difference in the age between the two groups was found to be statistically significant ( $P$ Value $<0.001$ ) 
Table 1: Comparison of baseline parameters between study groups $(\mathrm{N}=120)$

\begin{tabular}{|c|c|c|c|c|}
\hline \multirow{3}{*}{ Parameter } & \multicolumn{3}{|l|}{ Study group } & \multirow{3}{*}{$P$ value } \\
\hline & \multicolumn{2}{|l|}{ Cases $(n=80)$} & \multirow{2}{*}{ Control $(n=40)$} & \\
\hline & Group $1(n=40)$ & Group $2(n=40)$ & & \\
\hline \multicolumn{5}{|l|}{ Gender (N (\%)) } \\
\hline Male & $20(50 \%)$ & 20 (50\%) & $20(50 \%)$ & \multirow{2}{*}{1.000} \\
\hline Female & $20(50 \%)$ & $20(50 \%)$ & $20(50 \%)$ & \\
\hline $\begin{array}{l}\text { SBP(mmHg) } \\
\text { (Median (IQR)) }\end{array}$ & $130(120,136)$ & $120(110,130)$ & $120(110,120)$ & $<0.001$ \\
\hline $\begin{array}{l}\mathrm{DBP}(\mathrm{mmHg}) \\
\text { (Median (IQR)) }\end{array}$ & $80(70,80)$ & $80(70,80)$ & $80(70,80)$ & 0.953 \\
\hline $\begin{array}{l}\text { PR( per min) } \\
\text { (Median (IQR)) }\end{array}$ & $72(70,75.5)$ & $74(72,78)$ & $75(72,80)$ & 0.067 \\
\hline $\begin{array}{l}\text { Height (in cm) } \\
\text { (Median }(\mathrm{IQR}) \text { ) }\end{array}$ & $158.73 \pm 9.96$ & $155.38 \pm 4.71$ & $158.63 \pm 6.2$ & 0.235 \\
\hline $\begin{array}{lll}\text { Weight (in } & \text { kg) } \\
\text { (Median (IQR)) }\end{array}$ & $64.08 \pm 8.24$ & $68.05 \pm 7.32$ & $64.4 \pm 5.67$ & 0.155 \\
\hline $\begin{array}{l}\text { FBG(mg/dl) } \\
\text { (Median (IQR)) }\end{array}$ & $164(138,197)$ & $139(124.75,224.25)$ & $92.5(85.5,98.5)$ & $<0.001$ \\
\hline $\begin{array}{l}\text { PPBG(mg/dl) } \\
\text { (Median (IQR)) }\end{array}$ & $281(204.25,372)$ & $251.5(183.75,372.25)$ & $112(101.25,124.75)$ & $<0.001$ \\
\hline $\begin{array}{l}\text { HbA1c (\%) } \\
\text { (Median (IQR)) }\end{array}$ & $7.95(7.05,8.675)$ & $7.25(6.725,8.075)$ & $5.3(5.1,5.575)$ & $<0.001$ \\
\hline $\begin{array}{l}\mathrm{Mg} \quad(\mathrm{mg} / \mathrm{dl}) \\
\text { (Median }(\mathrm{IQR}) \text { ) }\end{array}$ & $1.85(1.7,1.975)$ & $2.1(1.9,2.2)$ & $2.1(2,2.2)$ & 0.003 \\
\hline $\begin{array}{l}\text { Urea(mg/dl) } \\
\text { (Median (IQR)) }\end{array}$ & $38(33.25,47)$ & $23(20,38)$ & $20(16.25,23)$ & $<0.001$ \\
\hline $\begin{array}{l}\text { Creatinine (mg/dl) } \\
\text { (Median (IQR)) }\end{array}$ & $1.4(1.1,2)$ & $1(0.8,1.1)$ & $0.8(0.725,1)$ & $<0.001$ \\
\hline
\end{tabular}

The difference between the values among both the case and control groups for certain parameters such as SBP, FBG, PPBG, HbA1c, Magnesium and Urea, Creatinine and were found to be statistically significant. Magnesium levels in cases were comparitively low when compared to control.

Table 2: Comparison of median $\mathrm{Mg}$ across diabetic retinopathy categories

\begin{tabular}{|l|l|l|}
\hline Diabetic Retinopathy & Mg Median (IQR) & $\begin{array}{l}\text { Kruskal Wallis test } \\
\text { (P value) }\end{array}$ \\
\cline { 1 - 2 } Mild NPDR (N=14) & $1.90(1.80,2.00)$ & \multirow{2}{*}{0.008} \\
\cline { 1 - 2 } Moderate NPDR (N=17) & $1.90(1.70,2.00)$ & \\
\cline { 1 - 2 } Severe NPDR (N =6) & $1.75(1.67,1.92)$ & \\
\cline { 1 - 2 } Proliferative retinopathy $(\mathrm{N}=3)$ & $1.8(1.69,2.0)$ & \\
\cline { 1 - 2 }
\end{tabular}

Among the study population with diabetic retinopathy, the difference between the median serum levels of magnesium among the NPDR categories was found to be statistically significant. ( $P$ value 0.008 )

\section{DISCUSSION}

The current study reported lower levels of serum magnesium in diabetic patients with and without retinopathy compared to the controls. These results are in line with the reports of Tosiello $L^{9}$, Kao WH et $\mathrm{al}^{10}$, Chamber E C et al ${ }^{11}$ and also by Baig MSA et $\mathrm{al}^{12}$, who have reported the similar findings. These reports are comparable to other studies suggesting that lower levels of serum magnesium would possibly be a potential risk factor in progress and development of diabetic retinopathy. Some studies ${ }^{13}$ have reported that hyperglycemia effects 
hypomagnesemia by causing depression in the net tubular reabsorption of magnesium.

In the present study mean $\mathrm{HbA1c}$ levels were significantly higher among the cases $(P<0.001)$, which was similar to those reported by Kundu $D$ et al. ${ }^{2}$, and also have reported that this indicates higher level of $\mathrm{HbA1c}$ is associated with increased risk for development of microangiopathy in diabetic patients. The actual reason leading to diabetic hypomagnesemia is still unidentified but an increased urinary loss of magnesium might sometimes lead to it. Hypomagnesaemia has been reported to occur more frequently among patients with type 2 diabetes compared to those without diabetes. In this study, magnesium levels were comparatively low when compared to controls. In cases, magnesium levels were in low normal range. Although many authors have recommended that diabetes may induce hypomagnesemia, others have reported that higher $\mathrm{Mg}$ intake may confer a lower risk for type 2 diabetes. ${ }^{14,}{ }^{15}$ The mechanisms through which hypomagnesemia may initiate or aggravate existing diabetes are not clearly understood. However, it has been suggested that hypomagnesemia may induce altered cellular glucose transport, reduced pancreatic insulin secretion, defective post receptor insulin signalling and altered insulin-insulin receptor interactions. ${ }^{16,17}$ In this study, low magnesium level in severe NPDR when compared to PR. This study has got the limitations such as non detection of impending diabetic nephropathy. Studies have indicated that, estimation of serum magnesium levels would be helpful to monitor the severity of complications among those with type 2 diabetes and also beneficial for proper and timely interventions. ${ }^{12}$

\section{CONCLUSION}

Hypomagnesemia is reported to occur more likely among patients with type 2 diabetes and might be a potential risk factor for retinopathy and further complications. Timely monitoring of serum magnesium levels as well as appropriate interventions would be beneficial.

\section{REFERENCE}

1. American Diabetes Association: National Diabetes Fact Sheet. 2002 [Available from: http:// www.diabetes.org/diabetes-statistics.

2. Kundu D, Osta M, Mandal T, Bandyopadhyay U, Ray D, Gautam D. Serum magnesium levels in patients with diabetic retinopathy. Journal of natural science, biology, and medicine. 2013;4(1):113.

3. WHO. Definition and Diagnoses of Diabetes 2005 [Available from: www.who.int/ diabetes/ publications.

4. Pham P-C, Pham P-M, Pham P-A, Pham S, Pham $H$, Miller J, et al. Lower serum magnesium levels are associated with more rapid decline of renal function in patients with diabetes mellitus type 2. Clinical nephrology. 2005;63(6).

5. Kim DJ, Xun P, Liu K, Loria C, Yokota K, Jacobs DR, et al. Magnesium intake in relation to systemic inflammation, insulin resistance, and the incidence of diabetes. Diabetes care. 2010;33 (12):2604-10.

6. Nadler JL, Malayan S, Luong H, Shaw S, Natarajan RD, Rude RK. Intracellular free magnesium deficiency plays a key role in increased platelet reactivity in type II diabetes mellitus. Diabetes care. 1992;15(7):835-41.

7. Mikhail N, Ehsanipoor K. Ionized serum magnesium in type 2 diabetes mellitus: its correlation with total serum magnesium and hemoglobin A1c levels. Southern medical journal 1999;92(12):1162-6.

8. Mooradian AD, Failla $M$, Hoogwerf $B$, Maryniuk M, Wylie-Rosett J. Selected vitamins and minerals in diabetes. Diabetes care. 1994;17 (5):464-79.

9. Tosiello L. Hypomagnesemia and diabetes mellitus: a review of clinical implications. Archives of internal medicine. 1996;156 (11): 1143-8.

10. Kao WL, Folsom AR, Nieto FJ, Mo J-P, Watson RL, Brancati FL. Serum and dietary magnesium and the risk for type 2 diabetes mellitus: the Atherosclerosis Risk in Communities Study. Archives of Internal Medicine. 1999;159 (18): 2151-9.

11. Chambers EC, Heshka S, Gallagher D, Wang J, PiSunyer FX, Pierson Jr RN. Serum magnesium and type-2 diabetes in African Americans and Hispanics: a New York cohort. Journal of the American College of Nutrition. 2006;25(6):50913.

12. Baig MSA, Shamshuddin $M$, Mahadevappa $K$, Attar AH, Shaikh AK. Serum magnesium as a marker of diabetic complications. J Evol Med Dent Sci. 2012;1(3):119-23.

13. Durak R, Gülen $Y$, Kurudirek $M$, Kaçal $M$, Çapoğlu i. Determination of trace element levels in 
Dr. I. Vijayapriya et al, International Journal of Medical and Biomedical Studies (IJMBS)

human blood serum from patients with type II diabetes using WDXRF technique: a comparative study. Journal of X-ray science and technology. 2010;18(2):111-20.

14. Song $Y$, Manson JE, Buring JE, Liu S. Dietary magnesium intake in relation to plasma insulin levels and risk of type 2 diabetes in women. Diabetes care. 2004;27(1):59-65.

15. Van Dam RM, Hu FB, Rosenberg L, Krishnan S, Palmer JR. Dietary calcium and magnesium, major food sources, and risk of type 2 diabetes in US black women. Diabetes care. 2006;29 (10):2238-43.

16. Dzúrik R, Stefíková K, Spustová V, Fetkovská N. The role of magnesium deficiency in insulin resistance: an in vitro study. Journal of hypertension. 1991;9:S314.

17. Durlach J, Altura B, Altura B. Highlights and summary of the 10th annual French Colloquium on Magnesium. Magnesium. 1983;2:330-6. 